\title{
Blended Learning Practices in Russian Higher Education: Benefits, Challenges, Perspectives
}

\author{
Marina Nikiforova \\ Ural State University of Economics, 8 Marta/ Narodnoy Voli St. 62/45, 620144 Ekaterinburg, Russia
}

\begin{abstract}
The COVID-19 pandemic and a forced lockdown in spring 2020 made us reconsider the way we deliver higher education. Today we are all adopting new teaching tools and methods and redesigning our materials to be meant for diverse educational contexts. The present paper deals with the phenomenon of blended learning, which is a relatively new approach in Russian higher education. We introduce and critically discuss the concept of blended learning and given our own experience and the data of the survey we have conducted we analyze the strengths and weaknesses of blended learning approach and assess the prospects of its implementation in Russian higher education.
\end{abstract}

\section{Introduction}

A forced shift to remote learning (synchronous and asynchronous) at all levels of education in Russia in March 2020 due to the COVID-19 pandemic is called by some educators a natural pedagogical experiment. As it turned out most education providers in Russia particularly those located in regions, were in fact completely unprepared to deliver educational programmes in a new format. Thus, serious problems of financial, technical, methodological, and psychological nature were to be solved in a matter of weeks and even days. Most important, all the stakeholders - education authorities, institutional leaders, teaching staff, students and their parents - all had to face the challenge.

The new academic year (2020-2021) for many higher education institutions in Russia began with another measure, which general idea was to combine in-person learning with remote (mainly online) learning in order to minimize the number of physical contacts inside the university but to still preserve some face-to-face interaction between students and teaching staff. Most educators call this mode of education delivery 'blended learning' [1-8], though there are some who prefer the term 'hybrid learning' [9]. Whatever term is used it is quite evident that as with full remote in spring 2020, the new learning model in autumn 2020 became a matter of necessity for Russian higher education rather than choice. And though this time all the stakeholders were far better prepared to new learning scenarios, it was again a challenge to face since blended learning in Russian higher education was an innovation that lacked both theoretical and practical background.

On the basis of some theoretical approaches and our own practical experience we aim in this paper to introduce and discuss the concept of blended learning, to outline its pros and cons and to evaluate the prospects of blended learning implementation in Russian higher education. We hope that the research results presented in the paper will be of value for 
institutional leaders and university teachers who are interested in the design, implementation and research into blended learning.

\section{Materials and Methods}

The paper uses general scientific methods of study: analysis, synthesis, deduction, generalization; special scientific methods: pedagogical observation and online-survey. The survey was created on Google Forms platform and contains both single-choice and multiple-choice questions. The survey was conducted at the end of December 2020 among the students of Ural State University of Economics on how they evaluated their experience of blended learning, which was organized at the university from September to December 2020. Altogether 70 students from first- to third-year of studies majoring in Information Technologies took part in the survey.

\section{Results and Discussion}

\subsection{The concept of blended learning}

According to the Guidance developed by the Quality Assurance Agency for Higher Education in June 2020, the term 'blended learning' can be applied "in several different ways to describe different models of delivery and/or student engagement" [10]. The Guidance emphasizes that "some institutions use the term blended as a generic term for provision that includes any element of digital learning. Blended is also associated with models of delivery which require students to engage with timetabled onsite learning activities across the academic year, in addition to engaging with digital learning activities between these times. It is also used where there is not a requirement for regular onsite attendance, but there may be options for students to attend in person should they choose (for example, residential study weekends)" [ibid].

Thus, when exploring blended learning practices we should bear in mind that the term itself may have diverse interpretations and different people may use it to refer to different things. That is to say, educators understand the idea of 'blending' very broadly: for some it can denote a mix of teaching methods, forms or/and approaches, for some a mix of digital technologies or/and electronic tools in the teaching process and so on.

Yet, according to S. Hrastinski's comprehensive literature review [7], there are two most frequently cited interpretations of blended learning - by C. R. Graham [1], and D. R. Garrison and H. Kanuka [2]. C. R. Graham understands blended learning as systems that "combine face-to-face instruction with computer-mediated instruction" [1]. D. R. Garrison and H. Kanuka define blended learning as "the thoughtful integration of classroom face-toface learning experiences with online learning experiences" [2]. Therefore, it is obvious that most scholars and educators focus on the educational context as the key element of 'blending' rather than on methods, tools, inclusivity, etc. But what is important here, in our opinion, is that the combination of these two types of educational context and consequently two types of education delivery cannot be perceived as merely a mix of classroom meetings with online sessions; blended learning should be understood as a pedagogical approach, which provides a purposeful, well-designed, systematic, integrated combination of inperson with online learning activities and assessment procedures (synchronous and asynchronous); learning outcomes, teaching methods and assessment criteria being specified. We also reckon that the crucial idea of 'blending' consists exactly in combining of two types of educational context so as to avoid (or at least minimize) the problems 
related to computer-mediated and in-person education delivery modes while taking advantage of all the positive features of both.

In order to better understand the concept of blended learning one can also explore numerous blended learning models and conceptualizations, developed by experts from leading European universities [1-6, 8]. The models elaborate on various characteristics of blended learning and thus, can be relevant for those involved in module, course or programme design and evaluation.

\subsection{Strengths and weaknesses of blended learning in Russian higher education}

Though we do understand that in Russian higher education blended learning is still in status nascendi, we reckon that some general conclusions are to be drawn and theoretical statements to be made.

Therefore, reflecting on our experience and given the results of the online-survey we have conducted, we can assume that the key advantage of the considered approach compared to 'purely' online learning or in-person one, is exactly the combination of two educational contexts (two types of learning environment) and therefore, most effective practices within each of these in order to achieve the desired learning outcomes. That is probably the first and foremost benefit of blended learning as a pedagogical approach and a syncretic form of education delivery when considered in the framework of outcome-based educational paradigm. The benefit was mentioned by $90 \%$ of respondents.

Speaking of other benefits that blended approach provides, we should especially note inclusiveness (mentioned by $44 \%$ of respondents), accessibility (mentioned by $82 \%$ of respondents), flexibility (mentioned by $88 \%$ of respondents), and cost-effectiveness (mentioned by $76 \%$ of respondents), though these are not specific to blended approach alone, but common to all digital learning scenarios. In fact, today we are all getting more and more technologically dependent and higher education is no exception. Technologies in education are meant to facilitate and enhance learning, to make it more personalized, effective and accessible, while cutting expenses of both individual learners and education organizations.

As to the weaknesses of blended learning, they are in fact weaknesses and limitations of all computer-mediated approaches: when we are speaking about challenges that confront students and university teachers practicing blended learning models we imply problems and limitations that arise when it comes to online learning.

Thus, all the challenges one can face when practicing online and consequently blended learning too, fall into three big groups:

1) financial and technical problems of all sorts: bad technical conditions on campus, no stable Internet access especially in rural areas, students having no proper workplace or / and electronic devices (was mentioned by $40 \%$ of respondents);

2) problems of methodological and digital nature: teaching staff lacking digital literacy or incapable of using innovative methodological approaches to transfer educational content, a badly-elaborated course-design, low-quality digitalized educational content, teaching methods that do not work in online settings, etc (was mentioned by $40 \%$ of respondents);

3) problems of psychological origin: students having a low level of responsibility and selfregulation, both students and teachers unwilling or unready to interact in the context of digital transformations, etc (was mentioned by $32 \%$ of respondents).

We should especially note that $20 \%$ of the respondents did not face any challenges (or probably did not find them significant enough to be mentioned) while practicing blended learning. And yet, as our survey shows many students are still experiencing problems or 
limitations of all sorts. Most important, some university teachers still feel they lack pedagogical and digital skills required for high-quality education delivery in a new context.

Of course, since March 2020 when we all had to convert to remote learning suddenly and involuntarily, the situation has improved significantly and today students, teachers and institutional leaders are far better prepared for learning and teaching in new contexts. And yet, as the survey shows there are still challenges to be taken. Thus, we believe that if blended learning is to be practiced on a regular basis, institutional leaders have to ensure that all necessary support is in place for both students and university teachers - from solving technical problems to providing the teaching staff with specific training [11].

Bearing in mind all the challenges to be taken, we should emphasize that the percentage analysis of pros and cons mentioned by students of USUE proves that most students consider blended learning to be a positive innovation in Russian higher education. What is also important is that most students evaluate their overall experience of blended learning as a positive one. Thus, besides the multiple-choice questions related to strengths and weaknesses of the considered approach we asked them to answer a few single-choice questions so as to understand their general impressions of blended learning experience. The questions and percentages are presented below.

1. To what extent are you satisfied with the blended learning system organized at USUE in the period from September 2020 to December 2020?

Completely satisfied $-20 \%$

Satisfied rather than not $-44 \%$

Satisfied only about several disciplines $-20 \%$

Completely unsatisfied $-16 \%$

2. To what extent are you satisfied with the quality of content transfer from the teacher to the students during online learning periods (workshops and lectures in Microsoft Teams and assignments to be done and submitted to the corporate e-learning platform)?

Completely satisfied $-20 \%$

Rather satisfied than not $-48 \%$

Satisfied only about several disciplines $-32 \%$

Completely unsatisfied $-0 \%$

3. To what extent are you satisfied with the quality of interaction between the teacher and the students during online learning periods (workshops and lectures in Microsoft Teams and assignments to be done and submitted to the corporate e-learning platform)?

Completely satisfied $-24 \%$

Satisfied rather than not $-44 \%$

Satisfied only about several disciplines $-24 \%$

Completely unsatisfied $-8 \%$

4. To what extent are you satisfied with the quality of assessment tasks meant to evaluate your knowledge and skills during online learning periods (workshops and lectures in Microsoft Teams and assignments to be done and submitted to the corporate e-learning platform)?

Completely satisfied $-36 \%$

Satisfied rather than not $-48 \%$

Satisfied only about several disciplines $-16 \%$

Completely unsatisfied $-0 \%$

5. To what extent, in your opinion, were the teachers prepared to practice blended learning approach? From the digital literacy perspective (whether they know how to use a computer, the Internet, applications, etc.) and methodological perspective (whether they know how to present learning materials and use adequate teaching methods and forms in elearning settings)?

All the teachers were completely prepared $-12 \%$ 
Most teachers were prepared $-68 \%$

Most teachers were completely unprepared $-16 \%$

All the teachers were completely unprepared $-4 \%$

6. Do you think that blended learning will be practiced in Russian higher education on a regular basis even when the COVID-19 pandemic is over?

Yes, I'm sure that blended learning will be practiced on a regular basis- $32 \%$

I'm not sure, but I admit that blended learning can be practiced in some higher education organizations- $36 \%$

No, I think that after the pandemic Russian higher education will convert back to 'purely' in-person learning - $24 \%$

I would prefer that higher education in Russia preserve 'purely' in-person learning $-8 \%$.

Therefore, despite the existing problems and limitations most students perceive blended learning as an effective approach; most student are positive about their blended learning experience and believe that blended learning practices can be implemented in Russian higher education.

\subsection{Perspectives of blended learning implementation in Russian higher education}

Speaking generally of blended learning perspectives in Russian higher education, we assume that blended learning can be especially beneficial for students on Master's degree programmes (and sometimes for part-time students on Bachelor's ones), since it can enable them to better combine their work, studies and family issues. Most important, due to a relatively small study load and a limited set of courses, Master's degree programmes can be rather easily transformed and adapted to blended learning settings, though some course redesigning can be mandatory. The blended learning scenario for such programmes might be as follows: online-lectures (recorded or real-time) and classroom-based or online synchronous workshops, at which group work and discussions on the subject are encouraged; electronic tests are completed and assessed online, individual written assignments submitted to the corporate e-learning platform, and individual, pair or group projects presented in class; feedback on students' progress is provided both through online tools and during in-person meetings.

When considering blended learning implementation in a longer-term perspective and not only for part-time students, we should admit that the process will inevitably demand a lot of time and effort to take. This is due to the longer duration of any Bachelor's degree programme, a wider range of courses within the programme, a larger number of students and teachers engaged in the teaching process.

Therefore, since blended learning is a relatively new phenomenon in Russian higher education, while some European educators have been practicing it for decades already, we believe that the best European practices can and should be adopted in order to facilitate blended learning implementation in Russian higher education as well. Thus, we find relevant the European Maturity Model for Blended Education [8] developed in a partnership of seven European higher education organizations. The model can be applied to three levels of blended learning implementation: course, programme and institutional, each presenting a set of maturity dimensions and key principles of implementation. For instance, the course level consists of the following four dimensions and corresponding subdimensions: 1 . course design process (selection of blended learning activities and their sequence; selection of blended learning tools), 2. course flexibility, 3. course interaction, 4. course experience (student learning, study load, inclusiveness) [ibid]. The model can be particularly handy for practitioners and educators involved in module / course / programme design and evaluation. 
We as well consider essential that Russian educators take part in international projects in order to adopt the world best innovative experiences, techniques, methods, and ultimately find most adequate ways to integrate them into Russian educational contexts.

\section{Conclusions}

Given the literature research into blended learning, the results of the survey we have conducted, and our own practical experience, we can draw the following conclusions.

1. Blended learning is a broad term and can be interpreted in many different ways. Yet, most researchers and practitioners understand blended learning as a pedagogical approach and a form of education delivery, which implies a thoughtful combination of in-person and online learning activities.

2. Blended learning is rather an innovation in Russian higher education. Yet, it has been observed that blended learning can be beneficial for students in many ways. It contributes to inclusivity, accessibility and flexibility of higher education, while reducing expenses of both students and education organizations.

3. The weaknesses of blended learning approach are common to all e-learning scenarios and basically can be grouped as follows: financial and technical limitations, methodological problems, and problems of psychological origin.

4. The prospects of blended learning implementation in Russian higher education vary by the educational programmes. Thus, for example, Bachelor's degree programmes in order to ensure blended learning on a regular basis have to be thoroughly redesigned and transformed in many ways while Master's degree programmes can be far more easily adapted to 'blended' scenarios. In order to facilitate blended learning implementation in Russian higher education it is important that some best European practices be adopted.

Summing it all up, we should again emphasize that time has enabled us to see numerous benefits of digital technologies and reconsider the way we impart knowledge in higher education. Since March 2020 the situation has changed a lot: we have significantly improved our digital and methodological skills, we are actively adopting new methods and techniques and redesigning our learning materials to be presented in various educational contexts. And yet, there are still challenges to be taken. Thus, we believe, that implementing blended learning as a pedagogical approach and a form of education delivery is sure to be a hard but practically feasible task for Russian education institutions. For if we want to provide quality higher education in Russia we have to keep up with the world innovative approaches and educational trends and to meet the needs of both individual learners and the labour market.

\section{References}

1. C. R. Graham, Blended learning systems: Definition, current trends and future directions (2006)

2. D. R. Garrison, H. Kanuka, (2004), Internet and Higher Education, 7 (2004)

3. C. R. Graham, W. Woodfield, J. B. Harrison, The Internet and Higher Education, 18 (2013)

4. M. Bower, B. Dalgarno, G. E. Kennedy, M. J. Lee, J. Kenney, Computers \& Education, 86 (2015).

5. R. M. Bernard, E. Borokhovski, R. F. Schmid, R. M. Tamim, P. C. Abrami, Journal of Computing in Higher Education, 26 (2014) 
6. A. Norberg, C. D. Dziuban, P. D. Moskal, On the Horizon, 19 (2011)

7. S. Hrastinski, TechTrends, 63 (2019)

8. W.F. van Valkenburg, W.P. Dijkstra, B. de los Arcos, K. Goeman, V. van Rompaey, S, Poelmans, European Maturity Model for Blended Education (2020)

9. A. Cohen, R. T. Nørgård, Y. Mor, British Journal of Educational Technology, 51 (2020)

10. The Quality Assurance Agency for Higher Education, Building a Taxonomy for Digital Learning: Guidance (2020), https://www.qaa.ac.uk/

11. N. Wise, M. Vidrevich, I. Pervukhina, E3S Web of Conferences, 208 (2020) 